\title{
Medicine and humanism
}

\section{Adolfo Saadia*}

$\mathrm{T}$ he editorials of Walter Gomes/Enio Buffolo and Domingo Braile published in BJCVS 21.4 give a practical and real feeling to such a controversial subject.

My greatest concern is currently concentrated on the development of technological processes at such a dizzy pace. We note that information technology is quickly transforming our concepts. We are not talking of decades or even 5-year periods in order to accept changes. I can say that changes are happening practically permanently. Internet search engines and blogs were unimaginable things for many of us such a short time ago. Not to mention nanotechnology that, when it is applied, will force us to find terms to describe the wonder of its use.

This unstoppable process, of great intellectual richness, but very difficult assimilation due to its profusion and speed, concerns me greatly:

How can we maintain medical humanism and the humanitarian relationship with our patients?

We can see there is confusion in the values that are entangled in the routine practices of health professionals in their day-to-day work. These considerations emerge from the conditions and indications of surgical interventions in our specialty and from the words of Enio, that is, there is a growing necessity to carefully analyze in which way knowledge and technology should be applied to the pathology on which we should act in order to maintain the basic premises of our profession.
It is necessary to avoid the jubilation or the influence of strange factors in our work, which are manual and fundamentally directed to fellow creatures.

I have always insisted in the necessity of developing, in university careers, especially in those related to healthcare, a 'complete' education including philosophy, anthropology and bioethics. This does not signify that we need to return to the classical humanities.

Nowadays, a university professional should not be graduated without this education and a 'specialist' should not be considered a specialist if he ignores the social problems, but he must evolve with a renovating spirit and humanistic feelings.

I believe all these concepts can, today and in the future, balance technoscience with humanism, as is equivocally attempted in some debates.

I am aware that I have distanced myself from specific details regarding the surgical theme, but I believe this is valid.

I changed my ideas when I was listening to Enio during his visit to Buenos Aires.

* Cardiovascular Surgeon. Titled member of the Argentinean Medical Association and of the Argentinean Surgery Society: Emeritus member of the Argentinean College of Cardiovascular Surgeons (CACCV): Member of the editorial board of the Argentinean Journal of Cardiovascular Surgery and of the Periodic Bulletin of CACCV 